\title{
Clinical Examination and Ultrasonography as Predictors of Lateral Neck Lymph Nodes Metastasis in Primary Well Differentiated Thyroid Cancer
}

\author{
Anwar Tawfik Amin'1 ${ }^{*}$, Khalid M. Rezk ${ }^{1}$, Haisam Atta ${ }^{2}$ \\ ${ }^{1}$ Department of Surgical Oncology, South Egypt Cancer Institute, Assiut University, Assiut, Egypt \\ ${ }^{2}$ Department of Diagnostic Radiology, South Egypt Cancer Institute, Assiut University, Assiut, Egypt \\ Email: *Adress:anwar71@oita-u.ac.jp
}

How to cite this paper: Amin, A.T., Rezk, K.M. and Atta, H. (2018) Clinical Examination and Ultrasonography as Predictors of Lateral Neck Lymph Nodes Metastasis in Primary Well Differentiated Thyroid Cancer. Journal of Cancer Therapy, 9, 55-63. https://doi.org/10.4236/jct.2018.91007

Received: October 6, 2017

Accepted: January 23, 2018

Published: January 26, 2018

Copyright $\odot 2018$ by authors and Scientific Research Publishing Inc. This work is licensed under the Creative Commons Attribution International License (CC BY 4.0).

http://creativecommons.org/licenses/by/4.0/

\begin{abstract}
Background: Lateral neck dissection is risky and should be performed only as a therapeutic intervention for known disease. Aim of the Study: This study aims at finding predictors which help in selecting patients who have high risk of lymph node metastasis. Methods: All the patients with well differentiated thyroid cancer underwent thyroidectomy with lateral lymph nodes (LNs) dissection with available pathology report and sufficient data have been included in the study. Results: Sixty nine patients have been included in this study. In multivariate analysis, the most reliable and significant factors for detecting L.N. involvement were the clinical picture and the U/S appearance of the Neck with $\mathrm{P}$ value of (0.008) and (0.001) respectively. Conclusion: Clinical and $\mathrm{U} / \mathrm{S}$ examinations are the most independent and reliable factors to detect lateral neck lymph nodes involvement.
\end{abstract}

\section{Keywords}

Thyroid, Cervical Lymphadenectomy, Thyroid Carcinoma, Neck

Ultrasonography

\section{Introduction}

According to American Thyroid Association (ATA), for optimal management of patients with thyroid cancer to be achieved, removal of cervical lymph nodes involved with metastases at the time of primary surgery is required. Lateral neck dissection should be performed only as a therapeutic intervention for known 
disease [1]. A prophylactic lateral neck dissection alone for thyroid cancer has not been proven effective to improve survival [2]. Lateral neck dissection is risky and could be associated with significant morbidity. A lateral neck dissection usually involves levels II, III, and IV lymph nodes which may endanger the spinal accessory, phrenic, vagus, cervical sensory, sympathetic trunk, hypoglossal, greater auricular, and the marginal mandibular branch of the facial nerves. In addition to nerve injury, chyle leak is another complication of performing a lateral neck dissection [3] [4] [5].

For lateral neck to be evaluated for metastatic disease, Physical examination, imaging studies such as ultrasonography (US) with or without FNAB which allows for mapping of central and bilateral neck compartments, iodine scans, CT, hybrid imaging modalities such as single photon emission computed tomography/CT and positron emission tomography/CT, technetium $99 \mathrm{~m}$ scintigraphy and magnetic resonance imaging can each be important in this regard. US performed by experienced hands is considered by most clinicians, and by the ATA, as the screening and surveillance imaging tool of choice for detection of lateral neck metastases [1].

Timing of lateral neck dissection for well-DTC is less critical than the central neck dissection for thyroid cancer or lateral neck dissection for squamous cell carcinoma of head and neck. Omitting of routine prophylactic central neck dissection may result in a revision surgery being necessary which could be challenging due to manipulating the same operative field of thyroidectomy with its resultant scar tissue [6].

As recommended by the ATA thyroid cancer guidelines, negative neck US findings in DTC imply that the lateral neck be managed expectantly [1]. In cases when a lateral neck node is enlarged $(>1.5 \mathrm{~cm}$ in levels I and IIa or $>1.0 \mathrm{~cm}$ in levels IIb-Vb) or has sonographic features suggesting disease, an US-guided fine-needle aspiration should be attempted to confirm disease. Testing the aspirate for thyroglobulin in a pauci-cellular specimen may be considered [3] [7] [8] Those nodes that have suspicious US characteristics and are not accessible to FNAB may be observed for progress with serial US at intervals recommended by the ATA before intervention.

Nodes less than 5 - $8 \mathrm{~mm}$, especially without worrisome features, might be observed rather than attempting an FNAB. The expected risks of lateral neck dissection should always be weighed against the possible benefits [1].

Lateral neck dissection performed for macroscopic DTC metastases should be the selective neck dissection of levels IIa, III, IV, and Vb. "Berry picking" is not recommended. As metastatic thyroid disease to levels I is infrequent; dissection of level $I$ is usually not indicated as it put the marginal mandibular branch of the facial nerve at risk, which might result in lower lip weakness [9]. Unless there are suspicious lymph nodes at level IIb or in the high jugular region (IIa); dissection above the accessory nerve (IIb) is generally not necessary. This could help to minimize postoperative morbidity associated with "shoulder syndrome", a condition of shoulder girdle weakness, stiffness and chronic pain that can arise when 
CN XI function is impaired [10]. In cases in which metastases were found at level V, they occurred almost exclusively at sublevel Vb. Sublevel Va was rarely, if ever, involved with metastatic lymph nodes therefore routine elective dissection of level Va may also be unnecessary. This further reduces the risk of injury to the accessory nerve [11].

This study aims at finding predictors which will help in selecting patients who have high risk of lymph node metastasis and need lateral neck dissection and to avoid unnecessary neck dissection.

\section{Patients and Methods}

This is a retrospective study in which all patients who had undergone thyroidectomy with lateral neck lymph nodes dissection for well differentiated thyroid cancer at South Egypt Cancer institute in the period from 2008 to 2012 have be reviewed. According to the definitions of the American Head and Neck Society and the American Academy of Otolaryngology-Head and Neck Surgery, lateral neck compartment extends from the carotid arteries to the medial border of the trapezius muscle and involves levels II, III, IV and V [12] [13] [14].

In this study, data about the primary tumor size, age, sex, thyroid capsular invasion; multi-focality of primary disease and histological type have been collected. The clinical evidences (palpable \pm hard LNs) as well as US evidences of lymph node involvement, have be evaluated as potential predictors of lateral lymph node metastasis. The US evidences of LN involvement was based mainly on loss of hilar echogenicity (fat center), poorly defined irregular borders, size > $5 \mathrm{~mm}$ in its shortest diameter and round shape [15] [16]. In this study, a node was considered suspicious if one or more of these criteria was met. Lateral LN dissection has been also done based on intraoperative evidences of metastasis even with negative clinical and ultra-sonographic data (probability of false negative clinical and US examination).

Included in this study were all patients with well differentiated thyroid cancer underwent thyroidectomy with lateral lymph nodes dissection that have available pathology reports and sufficient data. Excluded from this study were all patients with thyroid cancer other than will differentiated ones or patients with well differentiated thyroid cancer underwent thyroidectomy without lateral lymph nodes dissection or with no available pathology reports and no sufficient data.

Data have been collected from patient files and computerized data base at south Egypt cancer institute, Assiut University. Statistical analysis has been performed using STATA intercooled version 9.2. Quantitative data has been analyzed using Student $\mathrm{t}$ test or Mann-Whitney test when appropriate. Qualitative data has been compared using Chi square test. Univariate and multivariate logistic regression analysis has been done to detect factors that predict LNs involvement. $\mathrm{P}$ value has been considered significant if it was less than 0.05. The study was accepted by the ethical committee at south Egypt cancer institute. 


\section{Results}

Sixty nine patients who had undergone thyroidectomy with lateral neck lymph nodes dissection for well differentiated thyroid cancer at South Egypt Cancer institute in the period from 2008 to 2012 have been included in this study (Table 1).

In univariate analysis, lateral neck metastasis was more frequent in patients with papillary thyroid cancer, capsular invasion, positive clinical examination and positive U/S examination. No relationship could be detected for gender, age, tumor size or multi-focality.

All factors that were associated with lateral neck LN metastases were included in the multivariate regression analysis. In the multivariate analysis, the most reliable and significant factors for detecting L.N. involvement were the clinical picture and the U/S appearance of the Neck with P value of (0.008) and (0.001) respectively (Table 2 ).

Clinical examination could significantly detect involved LNs $(\mathrm{P} \leq 0.008)$ with sensitivity and specificity rate of $86.4 \%$ and $80.4 \%$ respectively.

Ultra-sonic examination could significantly detect involved LNs $(\mathrm{P} \leq 0.001)$ with sensitivity and specificity rate of $86.4 \%$ and $85.1 \%$ respectively.

Combined clinical and ultra-sonic examination could improve sensitivity to $95 \%$ but decrease specificity to $74 \%$.

Negative predictive value in combination of clinical examination and ultrasonography was $98 \%$ that is only $2 \%$ with truly positive lymph nodes will miss

Table 1. Clinico-pathological and US characteristics.

\begin{tabular}{cc}
\hline Variable & Value (\%) \\
\hline Total patient number & 69 \\
Male/Female & $16 / 53$ \\
Median age [range] & $41[19-78]$ \\
Pathology & \\
Papillary & $44(63.7 \%)$ \\
Follicular variant papillary & $15(21.7 \%)$ \\
Follicular & $10(14.6 \%)$ \\
Tumor size (cm) & $2(0.1-11)$ \\
Capsular invasion & $29(45.3 \%)$ \\
No capsular invasion & $40(54.7 \%)$ \\
Tumor multifocality & $19(27.5 \%)$ \\
Tumor non multifocality & $50(72.5 \%)$ \\
Clinically detected LNs & $28(40.6 \%)$ \\
Clinically non detected LNs & $41(59.4 \%)$ \\
U/S significant LNs & $26(37.7 \%)$ \\
U/S non-significant LNs & $43(63.3 \%)$ \\
Pathologically positive LNs & $22(32 \%)$ \\
Pathologically negative LNs & $47(68 \%)$ \\
\hline
\end{tabular}

LNs: Lymph nodes. 
Table 2. Significance of clinical picture and neck U/S in predicting lateral neck metastasis.

\begin{tabular}{|c|c|c|c|c|}
\hline \multirow{2}{*}{ Characteristics } & \multicolumn{2}{|c|}{ Pathologic lymph nodes status } & \multirow[t]{2}{*}{$\begin{array}{l}\text { Predictive } \\
\text { Value (PV) }\end{array}$} & \multirow[t]{2}{*}{$\mathrm{P}$ value } \\
\hline & -ve LNs $=47$ cases & +ve LNs $=22$ cases & & \\
\hline \multicolumn{5}{|c|}{ Clinical Examination (C/E) } \\
\hline -ve LNs & $\begin{array}{c}38 \text { cases } \\
\text { (True negative) }\end{array}$ & $\begin{array}{c}3 \text { cases } \\
\text { (False positive) }\end{array}$ & -ve PV: 93\% & \multirow{2}{*}{$<0.008$} \\
\hline +ve LNs & $\begin{array}{c}9 \text { cases } \\
\text { (False negative) }\end{array}$ & $\begin{array}{c}19 \text { cases } \\
\text { (True positive) }\end{array}$ & +ve PV: $68 \%$ & \\
\hline \multicolumn{5}{|c|}{ Ultrasonography (U/S) } \\
\hline -ve L.N. & $\begin{array}{c}40 \text { cases } \\
\text { (True negative) }\end{array}$ & $\begin{array}{c}3 \text { cases } \\
\text { (False positive) }\end{array}$ & -ve PV: 93\% & \multirow{2}{*}{$<0.001$} \\
\hline +ve L.N. & $\begin{array}{c}7 \text { cases } \\
\text { (False negative) }\end{array}$ & $\begin{array}{c}19 \text { cases } \\
\text { (True positive) }\end{array}$ & +ve PV: $73 \%$ & \\
\hline \multicolumn{5}{|c|}{ Combined (C/E\&U/S) } \\
\hline -ve L.N. & 40 (True negative) & 1 (False positive) & -ve PV: $98 \%$ & \\
\hline +ve L.N. & 7 (False negative) & 21 (True positive) & +ve PV: $75 \%$ & \\
\hline
\end{tabular}

lateral lymph node dissection. Also positive predictive value in combination of clinical examination and ultrasonography was $75 \%$ that is $75 \%$ of the patients with truly negative lymph nodes will avoid unnecessary lateral neck dissection (Table 2).

\section{Discussion}

From all included parameters in this study, only clinical examination and Neck $\mathrm{U} / \mathrm{S}$ were independent predictors of metastasis to lateral neck lymph nodes in well differentiated thyroid cancer.

Age, sex, capsular invasion and multi-focality as well as papillary thyroid cancer and tumor size were not predictive of lymph node metastasis in this research.

Several studies have described clinico-pathological factors associated with lymph node metastasis. But results from those studies were inconsistent [17] [18].

It's important to know whether or not tumor size is predictor of lymph node metastasis. Some studies have showed that L.N. metastasis is associated with large tumor size [19] [20] [21] [22]. However, our study and other studies reported that tumor size was not an independent predictor of lymph node metastasis in multivariate analysis [23] [24]. Also in the present study there is no correlation between age and LNs metastasis which is inconsistence with other earlier studies [23] [24]. Although a previous review has found an association between gender and lymph nodes metastasis [25] [26], we and Roh et al. have found that there was no association between gender and lymph nodes metastasis [24]. Moreover, we and Roh et al. found no relation between tumor multi-focality and lymph node metastasis [24]. 
In this study capsular invasion is not associated with lymph node involvement which is shown also by By et al. [20]. However, Moon et al. showed that minimal extra-thyroidal extension was significantly associated with lymph nodes metastasis [27].

We compared the preoperative clinical and imaging findings with the histopathological diagnosis. This study shows that, there is a strong association of lymph node metastasis with reported positive lymph nodes detected by clinical examination and neck US.

Negative predictive value for either clinical examination or ultrasonography examination of the neck was $93 \%$ for each. Positive predictive value for either of clinical examination or ultrasonography was $68 \%$ and $73 \%$ respectively. However, negative predictive value in combination of clinical examination and ultrasonography was $98 \%$ that is only $2 \%$ with truly positive lymph nodes will miss lateral lymph node dissection. Also positive predictive value in combination of clinical examination and ultrasonography was $75 \%$ that is $75 \%$ of the patients with truly negative lymph nodes will avoid unnecessary lateral neck dissection (Table 2).

Clinical examination has sensitivity of (86.36\%) and specificity of (80.85\%). The main advantage of accurate preoperative ultrasonography is that suspicious, yet non-palpable lymph nodes can be surgically considered. Neck US examination has sensitivity of (86.36\%) and specificity of (85.11\%).

By combining both clinical and Neck US examination, they had have sensitivity of $(95 \%)$ and specificity of (74\%).

This study has included only the cases with lateral neck dissection that have positive clinical and ultrasonography evidences of LNs metastasis, or negative clinical and US evidences with suspicious intraoperative evidences, therefore sensitivity and specificity could be estimated. However, prospective, large study could be more powerful in this regard.

Previously published studies also have shown substantially high values for sensitivity and specificity of ultrasound [3] [28] [29]. Stulak et al. showed sensitivity of 83.5 and specificity of 97.5 for primary well-differentiated thyroid cancer [3]. In cases of subsequent operations, sensitivity rose to $90.4 \%$ and specificity was $78.9 \%$ [3]. In recurrent well-differentiated thyroid cancer, $92.1 \%$ ultrasound sensitivity has been reported [29].

So both clinical examination and US examination could be reliable and effective tools to be used as preoperative predictors of lateral lymph nodes involvement in well differentiated thyroid cancer to avoid unnecessary lateral lymph node dissection.

This study has several limitations. First, this study is a retrospective; however, prospective study could be more powerful in this regard.

Second, since this study was retrospective analysis, the prognostic significance of lymph nodes metastasis such as the relation to tumor recurrence could not be investigated. Long-term follow up studies are needed to confirm the prognostic 
significance of lymph node metastasis. Third, our study population was a cohort of patients for a single center. Therefore, it is unlikely that this small cohort could provide reliable statements and a much larger number of cases in multicenter will be needed to generalize these results.

\section{Conclusion}

Clinical and US examinations are the most independent and reliable factors to detect metastasis in lateral neck lymph nodes. These two tools may be enough and efficient in detecting lateral lymph node involvement which could help in decision making for lateral lymph node dissection in well differentiated thyroid cancer.

\section{References}

[1] American Thyroid Association (ATA) Guidelines Taskforce on Thyroid Nodules and Differentiated Thyroid Cancer, Cooper, D.S., Doherty, G.M., Haugen, B.R., Kloos, R.T., Lee, S.L., Mandel, S.J., Mazzaferri, E.L., McIver, B., Pacini, F., Schlumberger, M., Sherman, S.I., Steward, D.L. and Tuttle, R.M. (209) Revised American Thyroid Association Management Guidelines for Patients with Thyroid Nodules and Differentiated Thyroid Cancer. Thyroid, 19, 1167-1214.

[2] Moreno, M.A., Agarwal, G., de Luna, R., Siegel, E.R., Sherman, S.I., Edeiken-Monroe, B.S. and Clayman, G.L. (2011) Preoperative Lateral Neck Ultrasonography as a Long-Term Outcome Predictor in Papillary Thyroid Cancer. Archives of Otolaryngology-Head and Neck Surgery, 137, 157-162.

https://doi.org/10.1001/archoto.2010.254

[3] Stulak, J.M., Grant, C.S., Farley, D.R., Thompson, G.B., van Heerden, J.A., Hay, I.D., Reading, C.C. and Charboneau, J.W. (2006) Value of Preoperative Ultrasonography in the Surgical Management of Initial and Reoperative Papillary Thyroid Cancer. Archives of Surgery, 141, 489-496.

https://doi.org/10.1001/archsurg.141.5.489

[4] Hay, I.D. (1990) Papillary Thyroid Carcinoma. Endocrinology and Metabolism Clinics of North America, 19, 545-576.

[5] Portinari, M. and Carcoforo, P. (2017) Complications of Bilateral Neck Dissection in Thyroid Cancer from a Single High-Volume Center. JAMA OtolaryngologyHead \& Neck Surgery, 143, 376-381. https://doi.org/10.1001/jamaoto.2016.3670

[6] Kim, M.K., Mandel, S.H., Baloch, Z., Livolsi, V.A., Langer, J.E., Didonato, L., Fish, S. and Weber, R.S. (2004) Morbidity Following Central Compartment Reoperation for Recurrent or Persistent Thyroid Cancer. Archives of Otolaryngology-Head and Neck Surgery, 130, 1214-1216. https://doi.org/10.1001/archotol.130.10.1214

[7] Kim, E., Park, J.S., Son, K.R., Kim, J.H., Jeon, S.J. and Na, D.G. (2008) Preoperative Diagnosis of Cervical Metastatic Lymph Nodes in Papillary Thyroid Carcinoma: Comparison of Ultrasound, Computed Tomography, and Combined Ultrasound with Computed Tomography. Thyroid, 18, 411-418.

https://doi.org/10.1089/thy.2007.0269

[8] Som, P.M., Curtin, H.D. and Mancuso, A.A. (2000) Imaging-Based Nodal Classification for Evaluation of Neck Metastatic Adenopathy. American Journal of Roentgenology, 174, 837-844. https://doi.org/10.2214/ajr.174.3.1740837

[9] Wu, G., Fraser, S., Pai, S.I., Farrag, T.Y., Ladenson, P.W. and Tufano, R.P. (2012) 
Determining the Extent of Lateral Neck Dissection Necessary to Establish Regional Disease Control and Avoid Reoperation after Previous Total Thyroidectomy and Radioactive Iodine for Papillary Thyroid Cancer. Head Neck, 34, 1418-1421. https://doi.org/10.1002/hed.21937

[10] Farrag, T., Lin, F., Brownlee, N., Kim, M., Sheth, S. and Tufano, R.P. (2009) Is Routine Dissection of Level II-B and V-A Necessary in Patients with Papillary Thyroid Cancer Undergoing Lateral Neck Dissection for FNA-Confirmed Metastases in Other Levels. World Journal of Surgery, 33, 1680-1683.

https://doi.org/10.1007/s00268-009-0071-x

[11] Khafif, A., Medina, J.E., Robbins, K.T., Silver, C.E., Weber, R.S., Rinaldo, A., Owen, R.P., Shaha, A.R. and Ferlito, A. (2013) Level V in Therapeutic Neck Dissections for Papillary Thyroid Carcinoma. Head Neck, 35, 605-607.

https://doi.org/10.1002/hed.21952

[12] Machens, A., Hauptmann, S. and Dralle, H. (2009) Lymph Node Dissection in the Lateral Neck for Completion in Central Node-Positive Papillary Thyroid Cancer. Surgery, 145, 176-181. https://doi.org/10.1016/j.surg.2008.09.003

[13] Sugitani, I., Fujimoto, Y., Yamada, K. and Yamamoto, N. (2008) Prospective Outcomes of Selective Lymph Node Dissection for Papillary Thyroid Carcinoma Based on Preoperative Ultrasonography. World Journal of Surgery, 32, 2494-2502. https://doi.org/10.1007/s00268-008-9711-9

[14] Choi, Y.J., Yun, J.S., Kook, S.H., Jung, E.C. and Park, Y.L. (2010) Clinical and Imaging Assessment of Cervical Lymph Node Metastasis in Papillary Thyroid Carcinomas. World Journal of Surgery, 34, 1494-1499. https://doi.org/10.1007/s00268-010-0541-1

[15] Lee, Y.S., Lim, Y.S., Lee, J.C., Wang, S.G., Son, S.M., Kim, S.S., Kim, I.J. and Lee, B.J. (2014) Ultrasonographic Findings Relating to Lymph Node Metastasis in Single Micropapillary Thyroid Cancer. World Journal of Surgical Oncology, 12, 273-279. https://doi.org/10.1186/1477-7819-12-273

[16] Lew, J.I., Rodgers, S.E. and Solorzano, C.C. (2010) Developments in the Use of Ultrasound for Thyroid Cancer. Current Opinion in Oncology, 22, 11-16. https://doi.org/10.1097/CCO.0b013e3283337f16

[17] Ryu, I.S., Song, C.I., Choi, S.H., Roh, J.L., Nam, S.Y. and Kim, S.Y. (2014) Lymph Node Ratio of the Central Compartment Is a Significant Predictor for Locoregional Recurrence after Prophylactic Central Neck Dissection in Patients with Thyroid Papillary Carcinoma. Annals of Surgical Oncology, 21, 277-283.

https://doi.org/10.1245/s10434-013-3258-1

[18] Raza, S.N., Shah, M.D., Palme, C.E., Hall, F.T., Eski, S. and Freeman, J.L. (2008) Risk Factors for Well-Differentiated Thyroid Carcinoma in Patients with Thyroid Nodular Disease. Otolaryngology_Head and Neck Surgery, 39, 21-26. https://doi.org/10.1016/j.otohns.2007.10.021

[19] Kasai, N. and Sakamoto, A. (1987) New Subgrouping of Small Thyroid Carcinomas. Cancer, 60, 1767-1770.

https://doi.org/10.1002/1097-0142(19871015)60:8<1767::AID-CNCR2820600816>3. $\underline{0 . \mathrm{CO} ; 2-\mathrm{P}}$

[20] Kim, B.Y., Jung, C.H., Kim, J.W., Lee, S.W., Kim, C.H., Kang, S.K. and Mok, J.O. (2012) Impact of Clinicopathologic Factors on Subclinical Central Lymph Node Metastasis in Papillary Thyroid Microcarcinoma. Yonsei Medical Journal, 53, 924-930. https://doi.org/10.3349/ymj.2012.53.5.924

[21] Pisanu, A., Deplano, D., Pili, M. and Uccheddu, A. (2011) Larger Tumor Size Pre- 
dicts Nodal Involvement in Patients with Follicular Thyroid Carcinoma. Tumori, 97, 296-303.

[22] Guerrero, M.A., Suh, I., Vriens, M.R., Shen, W.T., Gosnell, J., Kebebew, E., Duh, Q.Y. and Clark, O.H. (2010) Age and Tumor Size Predicts Lymph Node Involvement in Hurthle Cell Carcinoma. Journal of Cancer, 1, 23-26.

https://doi.org/10.7150/jca.1.23

[23] So, Y.K., Son, Y.I., Hong, S.D., Seo, M.Y., Baek, C.H., Jeong, H.S. and Chung, M.K. (2010) Subclinical Lymph Node Metastasis in Papillary Thyroid Microcarcinoma: A Study of 551 Resections. Surgery, 148, 526-531.

https://doi.org/10.1016/j.surg.2010.01.003

[24] Roh, J.L., Kim, J.M. and Park, C.I. (2008) Lateral Cervical Lymph Node Metastases from Papillary Thyroid Carcinoma: Pattern of Nodal Metastases and Optimal Strategy for Neck Dissection. Annals of Surgical Oncology, 15, 1177-1182. https://doi.org/10.1245/s10434-008-9813-5

[25] Lim, Y.C., Choi, E.C., Yoon, Y.H., Kim, E.H. and Koo, B.S. (2009) Central Lymph Node Metastases in Unilateral Papillary Thyroid Microcarcinoma. British Journal of Surgery, 96, 253-257. https://doi.org/10.1002/bjs.6484

[26] Sun, W., Lan, X., Zhang, H., Dong, W., Wang, Z., He, L., Zhang, T. and Liu, S. (215) Risk Factors for Central Lymph Node Metastasis in CN0 Papillary Thyroid Carcinoma: A Systematic Review and Meta-Analysis. PLoS ONE, 10, e0139021. https://doi.org/10.1371/journal.pone.0139021

[27] Moon, H.J., Kim, E.K., Chung, W.Y., Yoon, J.H. and Kwak, J.Y. (2011) Minimal Extrathyroidal Extension in Patients with Papillary Thyroid Microcarcinoma: Is It a Real Prognostic Factor? Annals of Surgical Oncology, 18, 1916-1923. https://doi.org/10.1245/s10434-011-1556-Z

[28] Kouvaraki, M.A., Shapiro, S.E., Fornage, B.D., Edeiken-Monro, B.S., Sherman, S.I., Vassilopoulou-Sellin, R., Lee, J.E. and Evans, D.B. (2003) Role of Preoperative Ultrasonography in the Surgical Management of Patients with Thyroid Cancer. Sur gery, 134, 946-955. https://doi.org/10.1016/S0039-6060(03)00424-0

[29] Frasoldati, A., Pesenti, M., Gallo, M., Caroggio, A., Salvo, D. and Valcavi, R. (2003) Diagnosis of Neck Recurrences in Patients with Differentiated Thyroid Carcinoma. Cancer, 97, 90-96. https://doi.org/10.1002/cncr.11031 